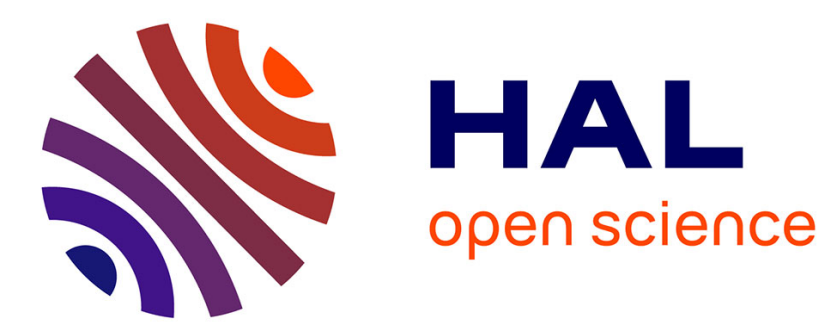

\title{
Behaviour and damage of injected carbon-fibre-reinforced polyether ether ketone: From process to modelling
}

Florentin Berthet, Frederic Lachaud, Jérémy Crevel, Marie-Laetitia Pastor

\section{- To cite this version:}

Florentin Berthet, Frederic Lachaud, Jérémy Crevel, Marie-Laetitia Pastor. Behaviour and damage of injected carbon-fibre-reinforced polyether ether ketone: From process to modelling. Journal of Composite Materials, 2017, 51 (2), p. 141-151. 10.1177/0021998316642000 . hal-01620032

\section{HAL Id: hal-01620032 https://hal.science/hal-01620032}

Submitted on 6 Nov 2019

HAL is a multi-disciplinary open access archive for the deposit and dissemination of scientific research documents, whether they are published or not. The documents may come from teaching and research institutions in France or abroad, or from public or private research centers.
L'archive ouverte pluridisciplinaire HAL, est destinée au dépôt et à la diffusion de documents scientifiques de niveau recherche, publiés ou non, émanant des établissements d'enseignement et de recherche français ou étrangers, des laboratoires publics ou privés. 


\title{
Behaviour and damage of injected carbon-fibre-reinforced polyether ether ketone: From process to modelling
}

\author{
F Berthet', F Lachaud ${ }^{2}$, J Crevel ${ }^{1,2}$ and M-L Pastor ${ }^{3}$
}

\begin{abstract}
Short-carbon-fibre-reinforced polyether ether ketones are materials of great interest for the aeronautical industry. In this study, a design of experiment was carried out to understand the effect of process parameters on micro- and macroscale properties of injection-moulded short-carbon-fibre-reinforced polyether ether ketone (90HMF40). Mould temperature was found to be the most significant parameter; it had a positive effect, essentially on failure stress and strain. Once the damage and plasticity scenarios were understood, a micromechanical model based on Mori-Tanaka homogenization theory was developed, featuring micro-damage and coupling with macro-plasticity. This model gave good predictions for quasi-static tensile tests.
\end{abstract}

\section{Keywords}

Polyether ether ketone, carbon fibre, injection moulding, modelling

\section{Introduction}

Composite materials are of major interest in the transport field, especially in aircraft construction, because of their excellent specific properties. ${ }^{1,2}$ They are made up of reinforcement particles lighter than commonly used materials, such as steel, which are incorporated in a resin to transfer stress. Thermosetting resins, such as epoxy, are used for their easy processing ${ }^{3}$ and good mechanical properties, but they are difficult to recycle. ${ }^{4}$ It is because they avoid this inconvenience that thermoplastic resins are of great interest. In addition, they have better impact and chemical (aeronautical fluids) resistance. $^{2,5}$ The aviation-certified-thermoplastic currently used is PEEK (polyether ether ketone), which has been largely investigated since its first commercialization by ICI in the 1980s. The addition of short carbon fibres considerably improves the mechanical properties of the composite. ${ }^{6}$ The best known carbonfibre-reinforced PEEK used in the aeronautical field is the unidirectional AS4-APC2 prepreg, manufactured in an autoclave. ${ }^{7}$ With this process, only simple and double curvature parts can be produced, and the injection-moulding technique is widely used for complex shapes. Moreover, short fibres can reinforce parts, depending on the distribution of their orientation, length and concentration. ${ }^{8,9}$ Hence, the major limitation of this process is related to the lower strength of materials obtained by injection compared to autoclaved laminated composites. ${ }^{10}$ Another problem encountered concerns the prediction of how the material will behave in a structure as the microstructure (fibre and matrix properties) can be altered by process parameters, leading to a heterogeneous material. Thus, it is essential to take these modifications into account when predicting material behaviour, a step that is not performed in a macroscopic model. The aim of the multi-scale modelling approach is to predict heterogeneous material behaviour from its microstructure and component properties. $^{11,12}$ The mean-field theory is one of the

'Ecole des mines Albi-Carmaux, ICA (Institut Clément Ader), Université de Toulouse, France

${ }^{2}$ ISAE-SUPAERO, ICA (Institut Clément Ader), Université de Toulouse, France

${ }^{3}$ IUT-Université Paul Sabatier, ICA (Institut Clément Ader), Université de Toulouse, France

\section{Corresponding author:}

F Berthet, Ecole des mines Albi-Carmaux, Allée des sciences, ICA (Institut Clément Ader), Université de Toulouse, Campus Jarlard, Albi 81013 CT Cedex 09, France.

Email: florentin.berthet@mines-albi.fr 
possible ways to attain this objective. This analytical path is easier to implement than full-field homogenization (based on finite elements) and is less time consuming. Shear lag models have been developed ${ }^{13,14}$ for injected material but are restricted to one dimension. Models based on Eshelby's solution with a non-dilute composite material enable a three-dimensional stiffness tensor to be predicted. Bounding models (Voigt, Reuss, Hashin-Shtrikman, Lielens) ${ }^{15-19}$ can monitor the validity of any models developed but are little used for mechanical prediction. The self-consistent model designed by $\mathrm{Hill}^{20}$ is implicit and results in the material being too stiff. However, the well-known Mori-Tanaka model, improved by Benveniste, ${ }^{21}$ is very efficient for fibre-reinforced-composites.

Thus, the aim of the present study was first to understand the effect of process parameters on micro- and macro-scale properties. In the case of injection-moulding, the main parameters of the microstructure: fibre length ${ }^{22,23}$ and orientation distributions, ${ }^{24-26}$ crystallinity, ${ }^{27}$ and fibre ${ }^{28}$ and void ${ }^{29}$ content, are altered by certain process parameters ${ }^{30-32}$ and have an effect on mechanical properties. ${ }^{33-35}$ Taguchi's table enabled the effect of injection-moulding parameters on traditional mechanical properties to be understood. Differential scanning calorimetry, density measurements, chemical dissolutions and section observations by scanning electron microscope (SEM) gave access to the microstructure state. Secondly, a Mori-Tanaka homogenization scheme was implemented using previously characterized microstructure parameters and variations. The non-linear behaviour of the matrix required a linearization of the problem in order to come within the domain of validity of the mean-field theory. ${ }^{36,37}$ In addition to problems of matrix nonlinearity, the bonding between fibres and resin is rarely perfect, ${ }^{38,39}$ so a damage criterion was implemented, based on the work of Fitoussi et al. ${ }^{40}$

\section{Experimental set-up}

\section{Material}

PEEK, a semi-crystalline thermoplastic polymer, has very good mechanical and chemical properties, ${ }^{5}$ see Table 1.

Moreover, it has a glass transition temperature of $143^{\circ} \mathrm{C}$ and a melting temperature of $343^{\circ} \mathrm{C}$, which enable it to be used at high temperature. ${ }^{2}$

In this study, a commercial grade carbon-fibre-reinforced PEEK was used: 90HMF40 provided by Victrex ${ }^{\circledR}$. The material contained $40 \mathrm{wt} \%$ of short carbon fibres (high-modulus carbon fibres with a mean length of $120 \mu \mathrm{m}$ ) and an easy flow PEEK grade. Test specimens, manufactured according to
Table I. Mechanical properties of PEEK (Victrex ${ }^{\circledR}$ PEEK $90 \mathrm{G}$ ).

\begin{tabular}{lcc}
\hline $\begin{array}{l}\text { Tensile Young's } \\
\text { modulus }(\mathrm{MPa})\end{array}$ & $\begin{array}{l}\text { Failure tensile } \\
\text { stress }(\mathrm{MPa})\end{array}$ & $\begin{array}{l}\text { Failure tensile } \\
\text { strain }(\%)\end{array}$ \\
\hline $3700 \pm 100$ & $110 \pm 1$ & $15 \pm 1$ \\
\hline
\end{tabular}

ASTM D3641-10a, ${ }^{41}$ were moulded with a DK 65/ 160 injection-moulding press.

\section{Design of experiments}

In order to understand the influence of processing parameters on mechanical and damage properties, an L9 Taguchi table was used ${ }^{42}$ (Table 2). It enabled four parameters to be varied on three levels. Each parameter was chosen according to physical limits and previous works. $^{43-46}$ Finally, the mould temperature ( $\left.T_{\text {mould }}\right)$ was chosen to be above the PEEK glass transition temperature and below the PEEK degradation temperature of $420^{\circ} \mathrm{C} .{ }^{47}$ The holding pressure $\left(P_{\text {hold }}\right)$ was chosen so as to avoid shrink (low-holding pressure) and flash (highholding pressure), and the holding time ( $\left.t_{\text {hold }}\right)$ (time for which the holding pressure was applied) and cooling time $\left(t_{\text {cool }}\right)$ (time from the end of holding time to part ejection) were also chosen in order to avoid cold slug. All parameter levels are given in Table 2. For $T_{\text {mould }}$, the levels were those measured during manufacturing. The temperature of the hopper was $50^{\circ} \mathrm{C}$, the barrel profile temperature was $385^{\circ} \mathrm{C}-390^{\circ} \mathrm{C}-395^{\circ} \mathrm{C}$, and the nozzle temperature was $405^{\circ} \mathrm{C}$ for all experiments. To obtain stable experimental results, the first five parts made in each trial were not taken into consideration.

\section{Characterization}

Monotonic and cyclic tensile tests were carried out on a testing machine with hydraulic grips respecting standard NF ISO $527-2,{ }^{48}$ with a crosshead speed of $5 \mathrm{~mm} /$ min (approximately $2 \mathrm{e}^{-3} \mathrm{~s}^{-1}$ ) at room temperature $\left(23^{\circ} \mathrm{C}\right)$. Young's modulus, strength and fracture strain were determined as the mean of at least three tensile tests. For cyclic tensile tests, special care was taken during the unloading of the stress, to avoid a compressive state.

In order to understand the damage phenomena after tensile tests, the fracture surfaces were observed by SEM with a Nova NanoSEM 450. Samples were platinum-palladium coated in a QUORUM Q150RS sputter coater to avoid electrical charges.

Temperature was measured during the tensile tests to understand the non-linear behaviour of the material. The infrared camera was a Flir SC7000 set to an acquisition frequency of $50 \mathrm{~Hz}$. Its operational range was from $+20^{\circ} \mathrm{C}$ to $50^{\circ} \mathrm{C}$ with a NETD lower than $25 \mathrm{mK}$ 
Table 2. L9 design of experiments.

\begin{tabular}{lcccc}
\hline Trial no. & $\begin{array}{l}\text { Mould } \\
\text { temp. }\left({ }^{\circ} \mathrm{C}\right)\end{array}$ & $\begin{array}{l}\text { Holding } \\
\text { pressure }(\mathrm{MPa})\end{array}$ & $\begin{array}{c}\text { Holding } \\
\text { time }(\mathrm{s})\end{array}$ & $\begin{array}{c}\text { Cooling } \\
\text { time }(\mathrm{s})\end{array}$ \\
\hline 1 & 178 & 60 & 6 & 35 \\
2 & 178 & 70 & 9 & 55 \\
3 & 178 & 80 & 12 & 80 \\
4 & 188 & 60 & 9 & 80 \\
5 & 188 & 70 & 12 & 35 \\
6 & 188 & 80 & 6 & 55 \\
7 & 203 & 60 & 12 & 55 \\
8 & 203 & 70 & 6 & 80 \\
9 & 203 & 80 & 9 & 35 \\
Test & 203 & 80 & 12 & 35 \\
\hline
\end{tabular}

at $25^{\circ} \mathrm{C}$. It featured an InSb detector with a wavelength of $3.5-5 \pm 0.25 \mu \mathrm{m}$ and a focal length of $50 \pm 0.5 \mathrm{~mm}$.

\section{Modelling}

\section{Mean-field homogenization}

The homogenization scheme chosen to predict the mechanical behaviour of the carbon-fibre-reinforced PEEK was the model first developed by Mori and Tanaka $^{49}$ and improved by Benveniste. ${ }^{21}$ Like all mean-field homogenization schemes, it is based on Eshelby's inclusion problem ${ }^{50}$ of the accommodation of an inclusion in a matrix. The theory considers an inclusion (for example, a fibre) embedded in the matrix. It is an analytical and explicit model in which the stiffness tensor $\left(\mathrm{L}_{\mathrm{MT}}\right)$ is given by equation (1). The equation can be solved by summing the effects of all phases.

$$
L_{M T}=L_{m}\left[I+\left\langle A_{r}\right\rangle\left(I+\left\langle\left(E_{r}-I\right) A_{r}\right\rangle^{-1}\right)\right]^{-1}
$$

where $A_{r}=-\left[\left(L_{r}-L_{m}\right) E_{r}+L_{m}\right]^{-1}\left(L_{r}-L_{m}\right)$ is the strain concentration tensor of the dilute Eshelby model, $\left\langle X_{r}\right\rangle=\sum_{r=1}^{N} v_{r} X_{r}$ is the volume average operator over the $N$ phases, $v_{r}$ is the volume fraction of phase $r, L_{r}$ (respectively, $L_{m}$ ) is the stiffness tensor of phase $r$ (respectively, the matrix), $E_{r}$ is the Eshelby tensor of phase $r$, depending on its aspect ratio (length/diameter) and matrix stiffness tensor.

For this model, with the Eshelby tensor, inclusions (fibres here) are considered as isotropic. This is true for glass fibres but not for carbon fibres. ${ }^{21}$ A new model using an 'autocoherent' methodology ${ }^{51}$ will be developed in order to take the orthotropic stiffnesses of carbon fibres into account. Although the anisotropy of carbon fibre was not considered here, we introduced the fibre orientation distribution as plotted in Figure 7. Then, as can be seen in Table 5, this distribution induced different values for longitudinal and transverse moduli.

\section{Non-linear behaviour: Elastoplastic phase}

In this study, plasticity is considered macroscopically. Based on the basic law of plasticity, equation (2) with Von Mises equivalent stress, equation (3), plasticity was implemented by an implicit formulation.

$$
\begin{gathered}
f=\sigma_{e q}-R(p) \\
\sigma_{e q}=\sqrt{\frac{3}{2} \cdot\left(\sigma-\frac{1}{3} \cdot \operatorname{tr}(\sigma)\right):\left(\sigma-\frac{1}{3} \cdot \operatorname{tr}(\sigma)\right)}
\end{gathered}
$$

The hardening law $R(p)$ was determined by an analysis of cyclic tensile tests.

$$
R(p)=R_{0}+R_{\text {crit }} \cdot[1-\exp (\gamma \cdot p)]
$$

A consideration of matrix plasticity, at micro scale, would require linearization of its mechanical behaviour, for example, with the secant method. ${ }^{7,8}$

\section{Non-linear behaviour: Damage criteria}

Considering elastic fibres and an elastoplastic matrix, it was easy to model fibre/matrix interface damage. This micromechanical damage depends on fibre orientation according to load orientation. For this type of composite, damage occurs at the fibre-matrix interface. ${ }^{40,51}$ Fitoussi determined a quadratic three-dimensional fibre-matrix interface failure criterion for discontinuous-reinforcement composite ${ }^{40}$ (equation (5)). It requires the identification of three parameters: $\sigma_{n}^{R}$, the interface failure normal stress; $\tau_{s}^{R}$, the interface failure shear stress and $\varphi$, the friction parameter. These parameters have been identified for unidirectional carbon fibre with PEEK matrix laminates by Lachaud. ${ }^{52}$ Thus, the criterion has to be calculated around the diameter of the interface, using the local axis for each orientation to take the anisotropy of the damage into account. A damage variable can be calculated as the ratio of the number of times; the criterion is satisfied for each angular position around the fibre to the total number of points calculated.

$$
\begin{cases}\left(\frac{\sigma_{n}^{i}}{\sigma_{n}^{R}}\right)^{2}+\left(\frac{\tau_{s}^{i}}{\tau_{s}^{R}}\right)^{2}=1 & \text { if } \sigma_{n}^{i}>0 \\ \left(\frac{\tau_{s}^{i}}{\left(\tau_{s}^{R}+\left\langle\sigma_{n}^{i}\right\rangle_{-} \tan (\varphi)\right)}\right)^{2}=1 & \text { if } \sigma_{n}^{i} \leq 0\end{cases}
$$




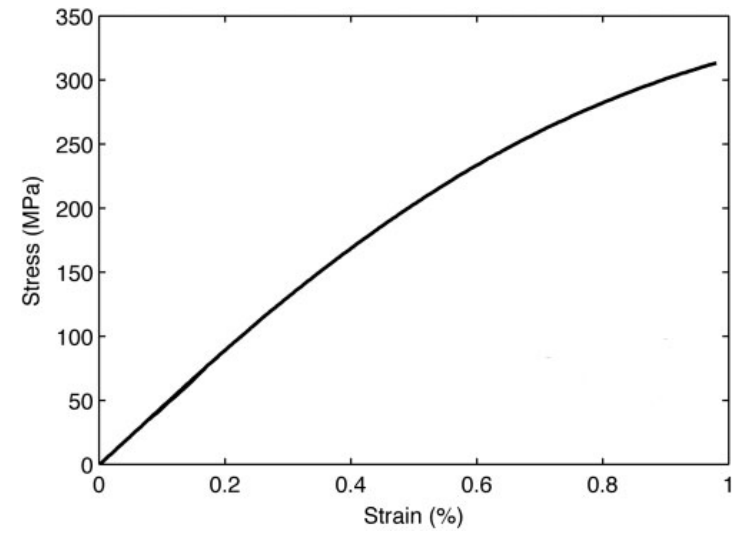

Figure I. Behaviour of $90 \mathrm{HMF} 40$ during quasi-static tensile tests (Trial no. 4 - first run).

Finally, a damage parameter was introduced in the stiffness matrix of the fibre in order to compute the global stiffness of the composite again.

\section{Results and discussion}

\section{Mechanical and physical properties}

The behaviour under quasi-static tensile loading is shown in Figure 1. The mean values of Young's modulus $(E)$, fracture strength $\left(\sigma_{R}\right)$ and strain $\left(\varepsilon_{R}\right)$ are reported in Table 3.

In Figure 2, three zones can be seen: Zone 1 $(\sigma<100 \mathrm{Mpa})$, an elastic zone; Zone $2(100 \mathrm{MPa}<$ $\sigma<260-270 \mathrm{MPa})$, where irreversible phenomena appear and Zone 3, a crack propagation region with a clear-cut increase in the average temperature.

The strength and failure strain of the 90HMF40 were high, so bonding between the fibre and the matrix might be good.

\section{Design of experiments, analysis}

Tensile results are given in Tables 3 and 4. The effects of injection parameters were determined (related to their levels) by multi-linear regression. It was possible to access the effects of parameters on the various results obtained from tensile tests (Figures 3 to 5). The ANOVA (analysis of variances) results are shown in Tables 5 to 7 . The results show that the mould temperature was the only significant factor affecting ultimate stress and strain.

Table 8 shows the effect of each injection parameter on the tensile properties for this PEEK.

At the levels of injection parameters use, holding pressure did not have a significant effect on tensile properties. The effects of holding time and cooling time were also not significant. Thus, mould temperature
Table 3. Tensile results.

\begin{tabular}{|c|c|c|c|}
\hline Trial no. & $\begin{array}{l}\text { Ultimate } \\
\text { stress (Mpa) }\end{array}$ & $\begin{array}{l}\text { Ultimate } \\
\text { strain (\%) }\end{array}$ & $\begin{array}{l}\text { Young's } \\
\text { modulus (Mpa) }\end{array}$ \\
\hline I & 299.2 & 0.89 & 43,076 \\
\hline I & 308.3 & 0.92 & 43,645 \\
\hline I & 304.6 & 0.89 & 44,432 \\
\hline 2 & 295.7 & 0.89 & 45,426 \\
\hline 2 & 317.4 & 1.00 & 42,456 \\
\hline 2 & 310.3 & 0.91 & 44,249 \\
\hline 3 & 297.0 & 0.91 & 44,708 \\
\hline 3 & 318.8 & 0.97 & 44,069 \\
\hline 3 & 321.5 & 0.97 & 44,180 \\
\hline 4 & 306.0 & 1.01 & 41,694 \\
\hline 4 & 330.7 & 1.10 & 43,267 \\
\hline 4 & 330.1 & 1.11 & 42,107 \\
\hline 5 & 319.4 & 0.99 & 45,559 \\
\hline 5 & 326.4 & 1.05 & 42,318 \\
\hline 5 & 320.3 & 0.99 & 43,986 \\
\hline 6 & 324.0 & 1.07 & 42,792 \\
\hline 6 & 332.5 & 1.17 & 40,135 \\
\hline 6 & 323.9 & 1.01 & 43,784 \\
\hline 7 & 310.1 & 0.96 & 44,617 \\
\hline 7 & 316.3 & 0.99 & 43,852 \\
\hline 7 & 318.4 & 1.02 & 42,654 \\
\hline 8 & 315.0 & 0.96 & 43,469 \\
\hline 8 & 331.7 & 1.12 & 42,870 \\
\hline 8 & 325.2 & 1.07 & 42,453 \\
\hline 9 & 316.5 & 1.00 & 43,845 \\
\hline 9 & 326.4 & 1.02 & 43,810 \\
\hline 9 & 316.4 & 0.94 & 43,783 \\
\hline Test & 316.7 & 0.95 & 45,690 \\
\hline Test & 319.6 & 0.99 & $44,2 \mid 4$ \\
\hline
\end{tabular}

was the most significant parameter, with a positive effect, essentially on failure stress and strain.

\section{Damage characterization}

In order to understand the damage behaviour, SEM microscopy was carried out (Figure 6). Two different mechanisms were noticeable: debonding (a) and matrix plasticity (b). This picture was taken on the fracture surface of a $90 \mathrm{HMF} 40$ specimen. It was observed that debonding was the most important phenomenon in the middle of the test specimen section, whereas matrix plasticity was the most prominent near the outer surfaces. Thus, PEEK transcrystallinity (growth of crystallinity perpendicularly to the fibre surface) had a significant effect on damage behaviour, as observed by Friedrich et al. ${ }^{53}$ and Kim and Gao. ${ }^{54}$ This crystallinity is highly influenced by cooling rates (thermal 


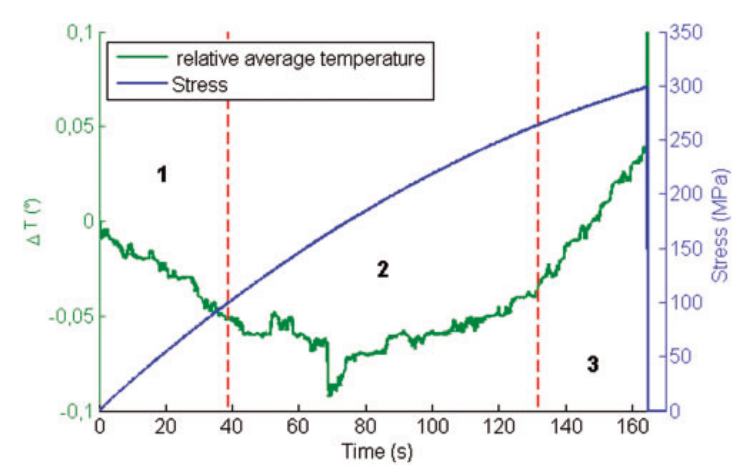

Figure 2. Stress and average relative temperature.

Table 4. Mechanical properties of $90 \mathrm{HMF} 40$.

\begin{tabular}{lllll}
\hline $\begin{array}{l}\text { Material } \\
\text { properties } \\
\text { of } 90 \mathrm{HMF40}\end{array}$ & Ex (GPa) & Ey (GPa) & $\sigma_{x}^{r}(\mathrm{MPa})$ & $\varepsilon_{x}^{r}(\%)$ \\
\hline $\begin{array}{l}\text { Tests } \\
\text { Numerical }\end{array}$ & $43.5 \pm 1.1$ & - & $317.1 \pm 10.2$ & $1.00 \pm 0.07$ \\
$\begin{array}{l}\text { model for } \\
\text { comparison }\end{array}$ & & 20.0 & - & - \\
\hline
\end{tabular}

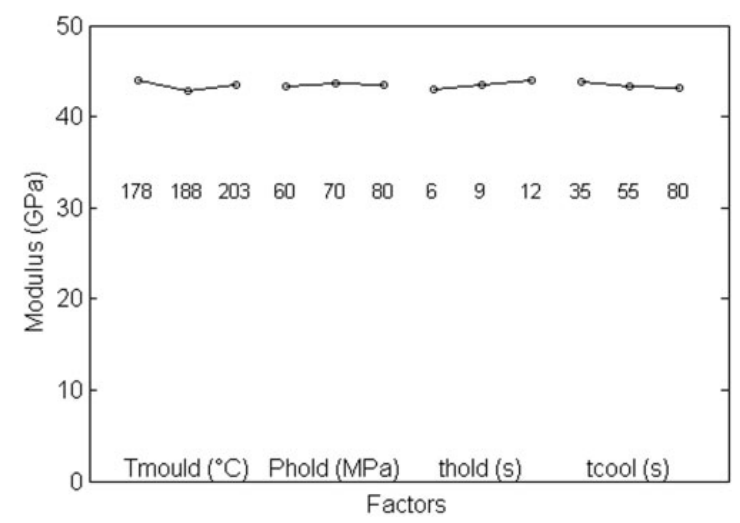

Figure 3. Effects of control factors on Young's modulus.

history), which themselves affect the mechanical properties of the matrix ${ }^{27}$ and matrix/fibre interface.

The cooling rate decreased at high mould temperature as the temperature of the injected composite was always the same. So, for higher mould temperature, the time to reach room temperature was longer. Then residual stresses decreased and influence initial damages. Figure 7 shows the relationship between damage energy (Yd) and damage. Figures 8 to 10 illustrate that high mould temperature decreased initial damage and had no significant influence on the other damage

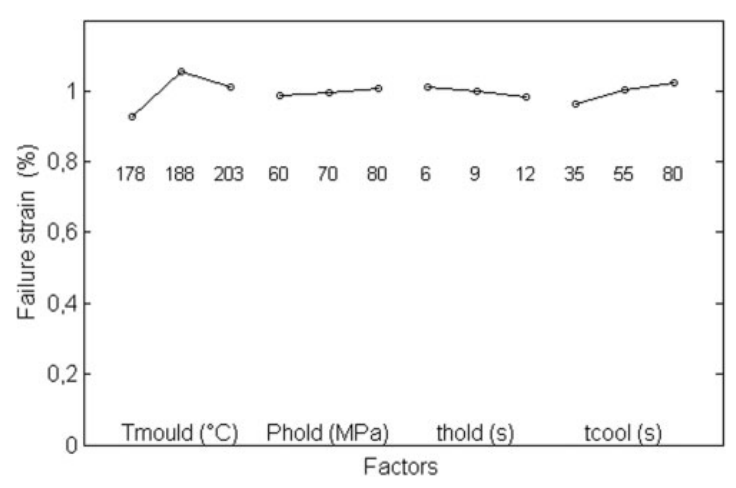

Figure 4. Effects of control factors on ultimate strain.

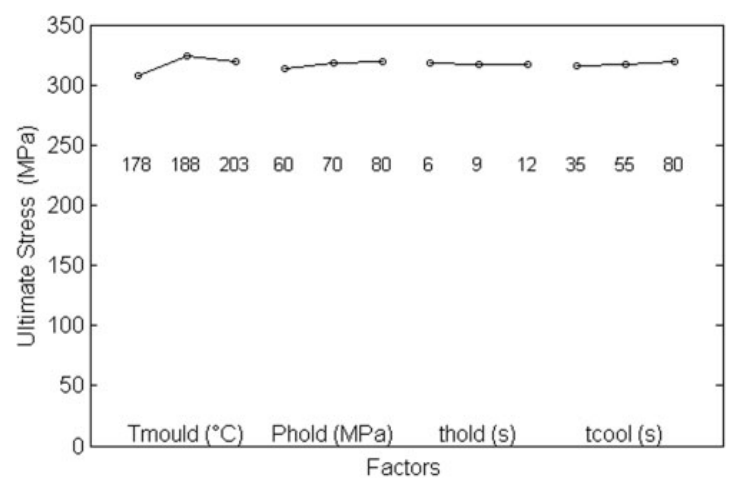

Figure 5. Effects of control factors on ultimate stress.

parameters. Thus, if initial damage decreased, the failure stresses and strains increased.

This can explain why mould temperature had a very significant effect on fracture strength and strain.

Furthermore, fibre orientation is directly impacted by matrix flow, ${ }^{6}$ which is influenced by fibre content, mould section and, of course, the thermal environment.

\section{Load-unload tensile tests}

For the non-linear behaviour of the material to be modelled, the damage and plasticity evolution laws and scenarios had to be determined, so load-unload tensile tests were carried out (Figure 11). The tests were strain controlled so as to keep a constant strain rate (very important for modelling).

\section{Modelling}

\section{Elastic homogenization}

The first step was to validate the global elastic prediction using the micro-parameters shown in Table 9, 
Table 5. ANOVA results for Young's modulus.

\begin{tabular}{lrrrrrrr}
\hline Source of variation & \multicolumn{1}{c}{$S$} & DOF & Variance & Fcalc & Risk & Signif & Contribution (\%) \\
\hline Temperature & $6,253,891$ & 2 & $3,126,946$ & 2.697 & 0.092 & No & 16.9 \\
Holding pressure & 659,047 & 2 & 329,523 & 0.284 & 0.756 & No & 1.8 \\
Holding time & $4,824,197$ & 2 & $2,412,098$ & 2.080 & 0.151 & No & 13.1 \\
Cooling time & $1,971,676$ & 2 & 985,838 & 0.850 & 0.442 & No & 5.3 \\
Error & $23,190,867$ & 20 & $1,159,543$ & & & & 62.8 \\
Total & $36,899,678$ & 26 & $1,419,218$ & & & & 100.0 \\
\hline
\end{tabular}

DOF: Degrees of freedom; ANOVA: analysis of variances.

Table 6. ANOVA results for strain.

\begin{tabular}{llllllrr}
\hline Source of variation & S & DOF & Variance & Fcalc & Risk & Signif & Contribution (\%) \\
\hline Temperature & $7.69039 \mathrm{E}-06$ & 2 & $3.8452 \mathrm{E}-06$ & 13.297088 & 0.0002123 & Yes & 49.15 \\
Holding pressure & $1.50503 \mathrm{E}-07$ & 2 & $7.52516 \mathrm{E}-08$ & 0.2602278 & 0.7734459 & No & 0.96 \\
Holding time & $3.7293 \mathrm{IE}-07$ & 2 & $1.86466 \mathrm{E}-07$ & 0.6448173 & 0.5353254 & No & 2.38 \\
Cooling time & $1.6486 \mathrm{E}-06$ & 2 & $8.24298 \mathrm{E}-07$ & 2.8505095 & 0.0814323 & No & 10.54 \\
Error & $5.78352 \mathrm{E}-06$ & 20 & $2.89176 \mathrm{E}-07$ & & & & 36.96 \\
Total & $1.56459 \mathrm{E}-05$ & 26 & $6.01767 \mathrm{E}-07$ & & & & 100.00 \\
\hline
\end{tabular}

ANOVA: analysis of variances; DOF: Degrees of freedom.

Table 7. ANOVA results for stress.

\begin{tabular}{lccccccr}
\hline Source of variation & \multicolumn{1}{c}{ S } & DOF & Variance & Fcalc & Risk & Signif & Contribution (\%) \\
\hline Temperature & 1174 & 2 & 587 & 7.94 & 0.00 & Yes & 40.13 \\
Holding pressure & 167 & 2 & 84 & 1.13 & 0.34 & No & 5.73 \\
Holding time & 18 & 2 & 9 & 0.12 & 0.89 & No & 0.60 \\
Cooling time & 87 & 2 & 44 & 0.59 & 0.56 & No & 2.98 \\
Error & 1479 & 20 & 74 & & & & 50.56 \\
Total & 2925 & 26 & 113 & & & & 100.00 \\
\hline
\end{tabular}

ANOVA: analysis of variances; DOF: Degrees of freedom.

where $l_{f}$ and $r_{f}$ are the fibre length and radius, respectively. A representative distribution of fibre length measured (Figure 12). A representative distribution of orientation was also taken on the basis of the experimental data (Figure 13). Samples were cut and observed with a microscope to determine the distribution of orientation by image analysis and computation.

\section{Non-linear prediction}

Once the elastic prediction was validated, we focused on the non-linear behaviour of the material. From the results of cyclic tensile tests, macroscopic isotropic hardening law parameters were determined (see Table 10) with the fit of the plastic curve determined by tensile tests (Figure 14). The matrix non-linear
Table 8. Effects of injection parameters on tensile properties for 90 HMF40.

\begin{tabular}{ll}
\hline Injection parameters & $90 \mathrm{HMF40}$ \\
\hline$T_{\text {mould }}$ & $E=/ \sigma_{r} / \varepsilon_{r} \nearrow$ \\
$P_{\text {hold }}$ & No effect \\
$t_{\text {hold }}$ & No effect \\
$t_{\text {cool }}$ & No effect \\
\hline
\end{tabular}

behaviour was thus modelled. Effects of control factors are given in Figure 15.

Moreover, Fitoussi et al. ${ }^{40}$ criteria parameters were determined by Eshelby ${ }^{50}$ for failure stresses (Table 10) by means of unidirectional laminate failure analysis. 


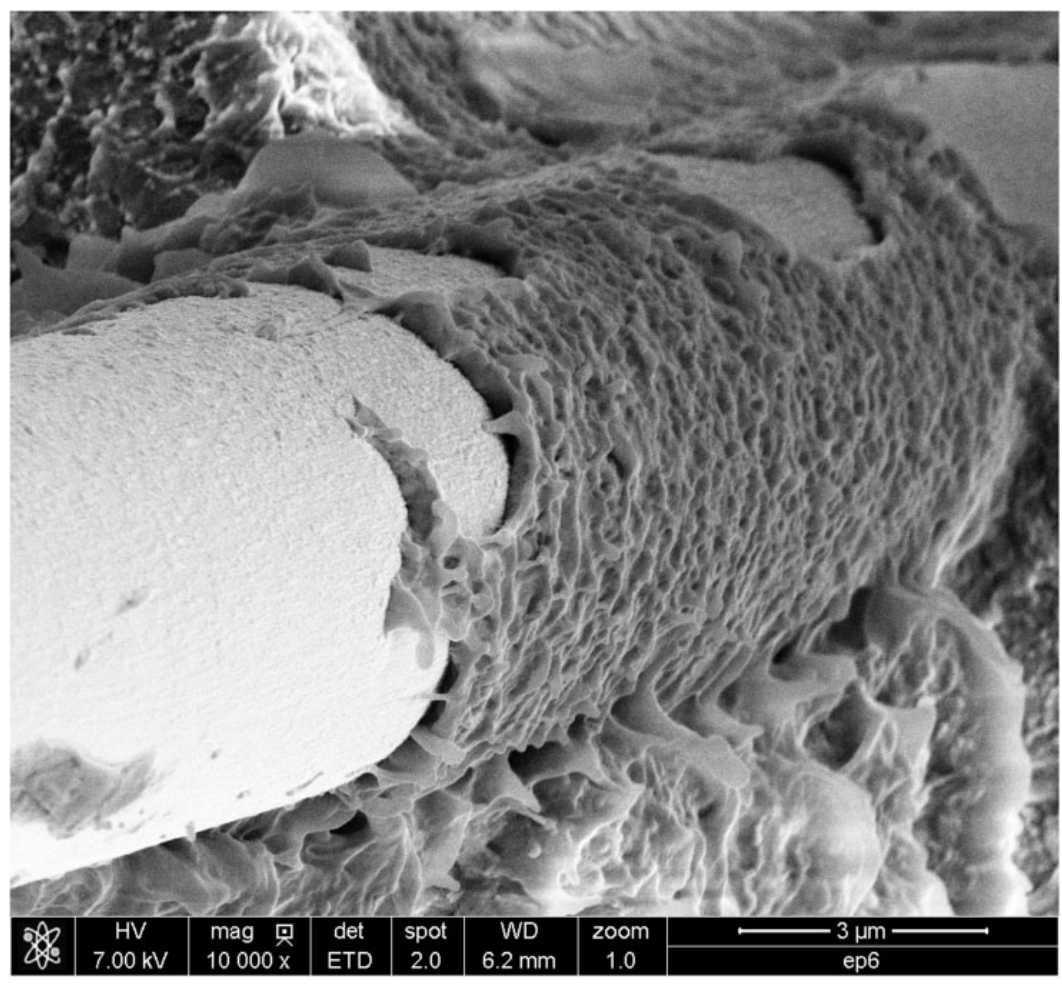

Figure 6. SEM image of fracture surface (debonding zone (a) and matrix plasticity (b)).

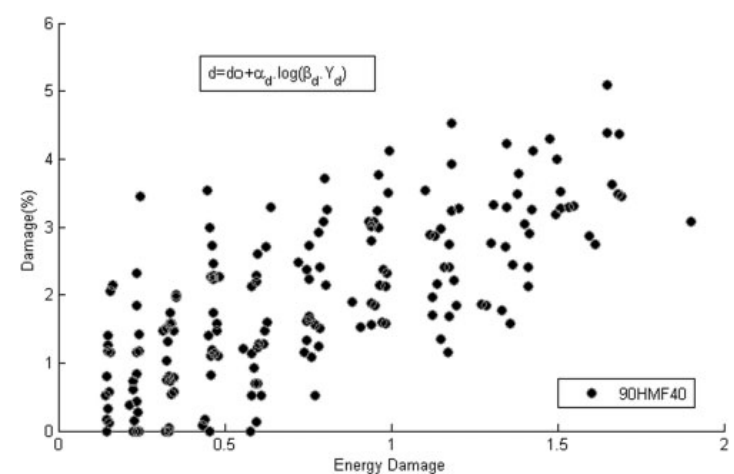

Figure 7. Damage vs. energy damage.

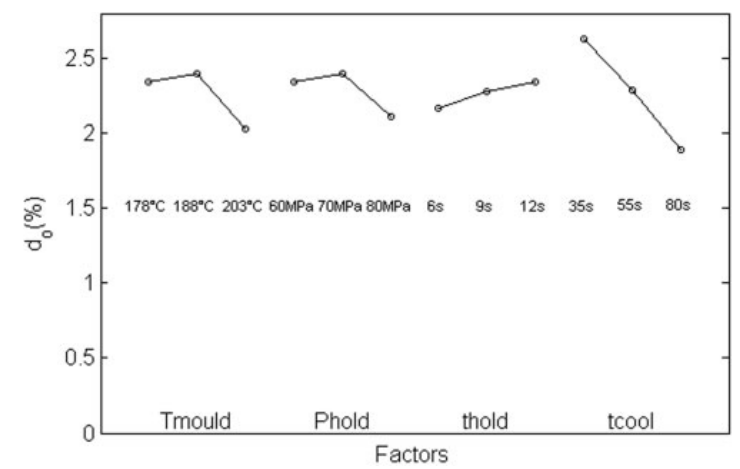

Figure 8. Effects of control factors on damage initiation.

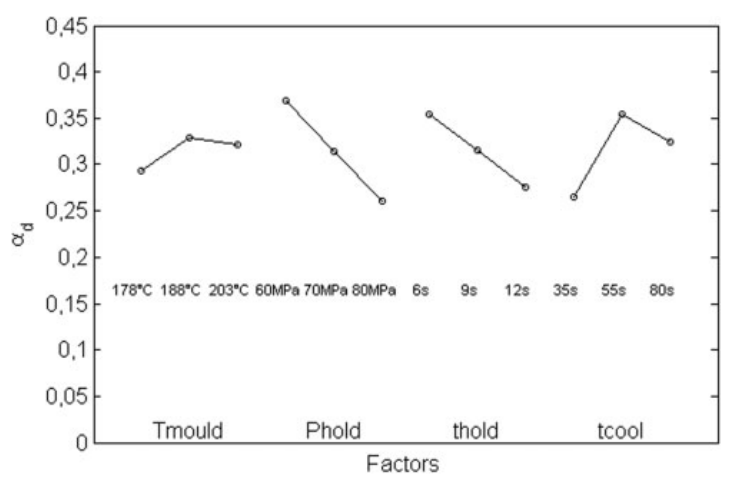

Figure 9. Effects of control factors on damage parameter $\alpha_{d}$.

The friction coefficient was assumed to take the classical value of 0.3 .

Finally, the prediction of the model was compared with experimental data obtained from monotonic tensile tests. As can be seen from Figure 16, there was fairly good agreement between the modeling prediction and the experimental data (error $<8 \%$ ). It should be noted that the experimental data corresponded to the experimental design and thus had an unusually wide dispersion. 
Table 9. Model parameters input to Mori-Tanaka model.

\begin{tabular}{llllllll}
\hline & \multicolumn{3}{c}{ Matrix } & & \multicolumn{5}{c}{ Fibre properties (Young's modulus in fibre direction) } \\
\cline { 2 - 3 } Material parameters & $E_{m}(\mathrm{GPa})$ & $v_{m}$ & & $E_{f}(\mathrm{GPa})$ & $v_{f}$ & $I_{f}(\mathrm{~m})$ & $r_{f}(\mathrm{~m})$ \\
\hline Parameter value & 3.8 & 0.325 & & 450 & 0.27 & Distribution & $2.5 \mathrm{e}^{-6}$ \\
\hline
\end{tabular}

Table 10. Parameters of the matrix.

\begin{tabular}{llllllll}
\hline & \multicolumn{3}{c}{ Hardening law } & & \multicolumn{3}{c}{ Fitoussi criteria } \\
\cline { 2 - 4 } \cline { 6 - 8 } Material parameters & $R_{0}(\mathrm{MPa})$ & $\mathrm{R}_{\text {crit }}(\mathrm{MPa})$ & $\gamma$ & & $\sigma_{\mathrm{n}}^{\mathrm{R}}(\mathrm{MPa})$ & $\tau_{\mathrm{s}}^{\mathrm{R}}(\mathrm{MPa})$ & $\phi$ \\
\hline Parameter value & $45 \pm 10$ & $240 \pm 40$ & $-2100 \pm 500$ & & $80.8 \pm 3$ & $165 \pm 10$ & 0.3 \\
\hline
\end{tabular}

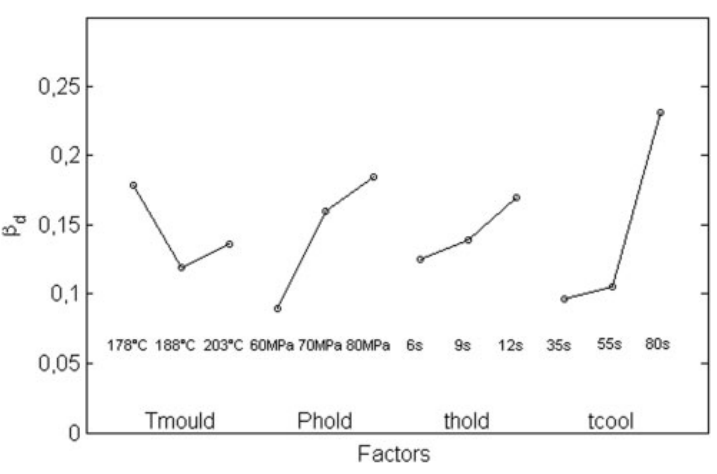

Figure 10. Effects of control factors on damage parameter $\beta_{\mathrm{d}}$.

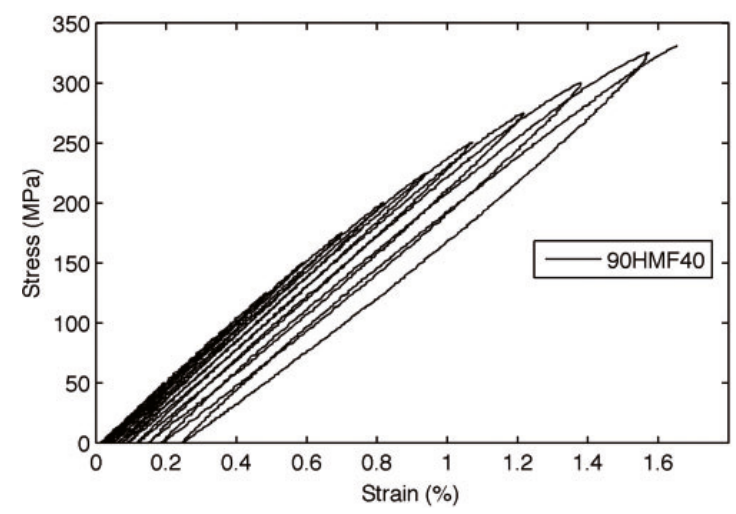

Figure II. Behaviour of $90 \mathrm{HMF} 40$ during load-unload tensile tests.

\section{Conclusions and perspectives}

Thanks to a design of experiments, it has been possible to determine the effects of process parameters on microstructure and, thus, on mechanical properties.

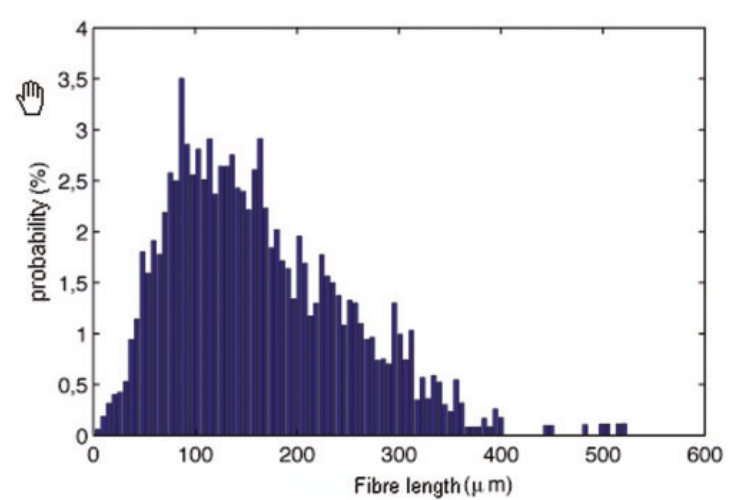

Figure 12. Fibre length distribution.

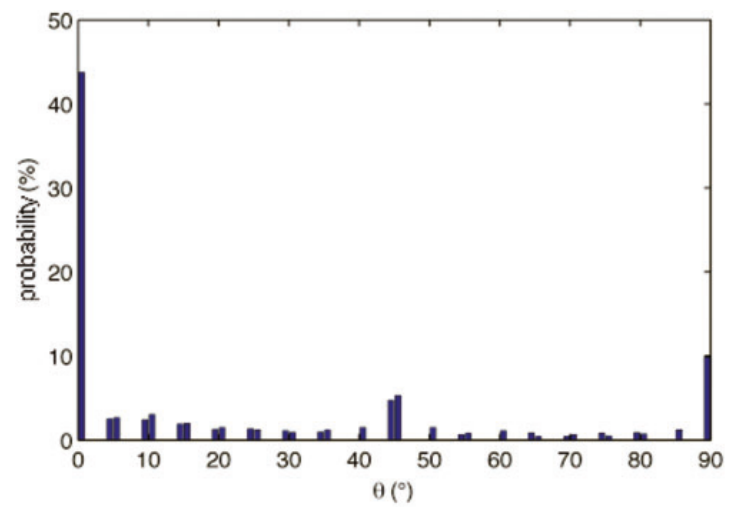

Figure 13. Fibre orientation distribution.

Observation of fracture surfaces revealed non-linear phenomena responsible for material failure. Tensile tests and cyclic (load-unload) tensile tests gave an understanding of the scenarios of damage and 
plasticity. Thanks to an infrared thermography analysis carried out during the tensile tests, the scenario was refined. A micromechanical model based on MoriTanaka homogenization theory was developed, featuring micro-damage and coupling with macro-plasticity, and gave a good prediction of quasi-static tensile test results. An extension to load-unload tensile tests is needed to check the model accuracy.

Possible perspectives include:

- Development of failure modelling of the short-fibrereinforced composite and integration of the model into the computations.

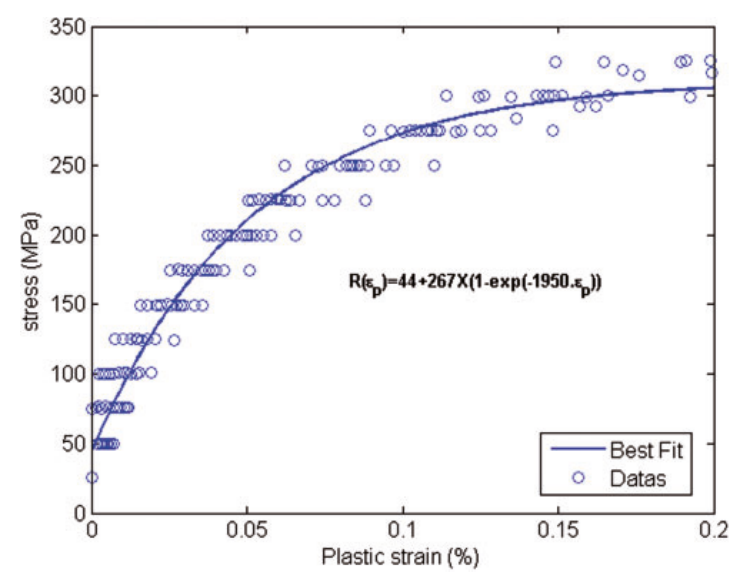

Figure 14. Stress vs. plastic strain for quasi-static cycled tests.
- 3D microstructurally based modelling and Simulation (with use of tomography).

- Behaviours temperature and time dependence of this carbon-fibre-reinforced PEEK.

- Simulation of deformation and damage, integration of matrix viscoelasticity into models, integration of plasticity at microscale, etc.

- Simulation of deformation and damage of this crystalline material during fatigue and creep.

- Integration of more sophisticated crystal plasticitybased models into mechanical behaviour simulation.

- Work on more advanced or enhanced interface criteria.

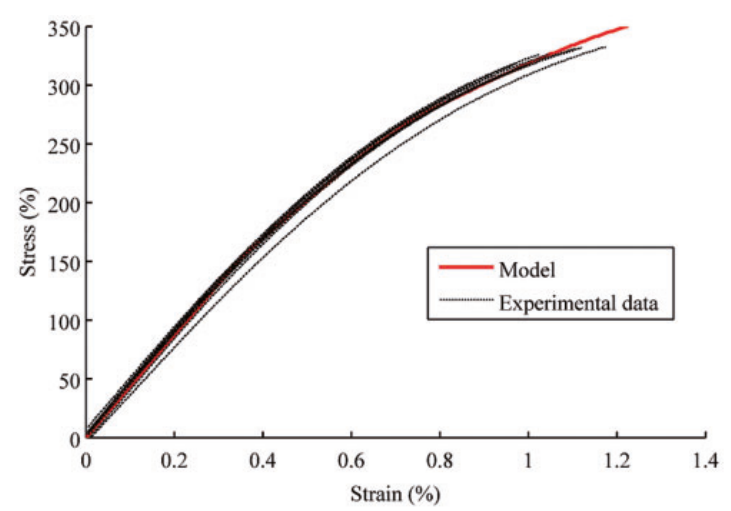

Figure 16. Prediction and experimental data for monotonic tensile test.
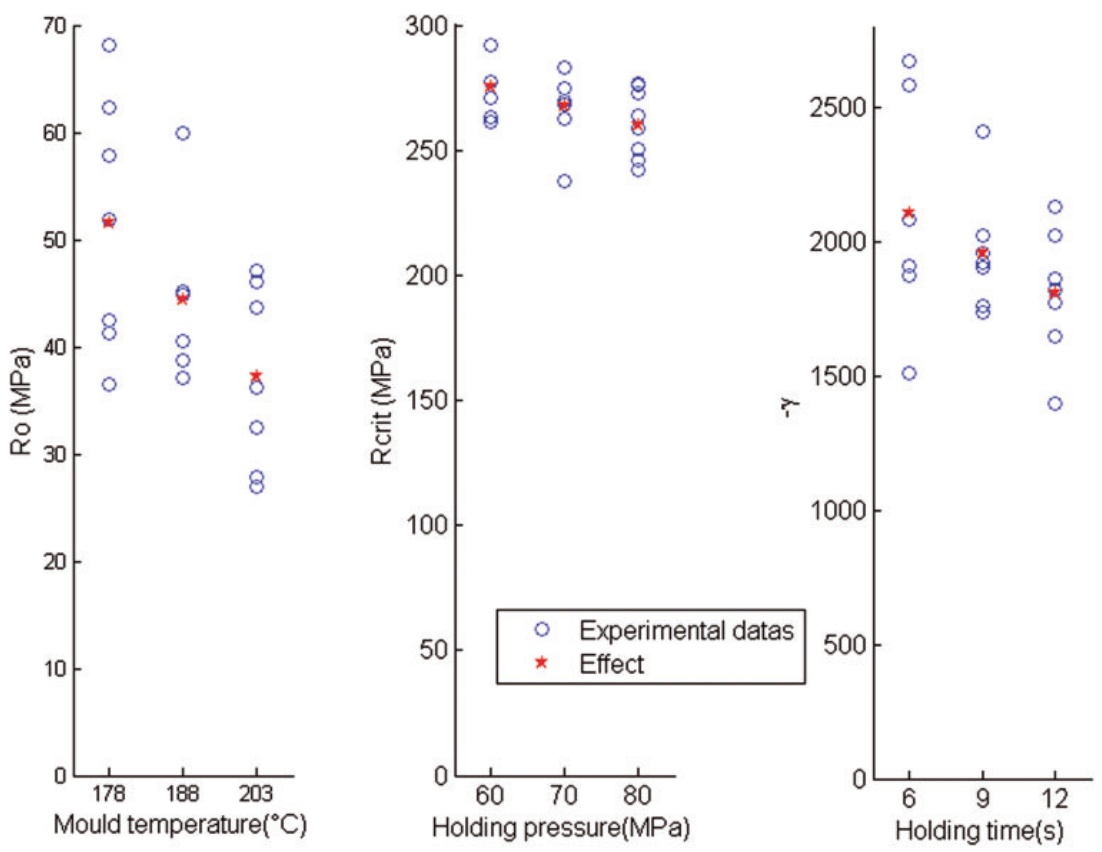

Figure 15. Significant process parameters for hardening law. 


\section{Declaration of Conflicting Interests}

The author(s) declared no potential conflicts of interest with respect to the research, authorship and/or publication of this article.

\section{Funding}

The author(s) received no financial support for the research, authorship and/or publication of this article.

\section{References}

1. Soutis C. Carbon fiber reinforced plastic in aircraft construction. Mater Sci Eng A 2005; 412: 171-176.

2. Denault $\mathbf{J}$ and Dumouchel $\mathbf{M}$. Consolidation process of PEEK/carbon composite for aerospace applications. $A d v$ Perform Mater 1998; 5: 83-96.

3. Grove S. Manufacture of polymer composites. Wiley encyclopedia of composites. Oxford: John Wiley \& Sons, 2012.

4. Pickering SJ. Recycling thermoset composite materials. Wiley encyclopedia of composites. Oxford: John Wiley \& Sons, 2012.

5. Sarasua JR, Remiro PM and Pouyet J. The mechanical behaviour of PEEK short fibre composites. J Mater Sci 1995; 30: 3501-3508.

6. Semadeni M, Zerlik H, Rossini P, et al. Injection moulding with high fiber volume fraction of carbon fiber reinforced Polyetheretherketone (PEEK) to increase mechanical properties. In: International SAMPE Europe conference, no. 19, Paris la Défense, 22-24 April 1998, pp. 315-321. Niederglatt, Switzerland: SAMPE Europe.

7. Hoa S. Principles of the manufacturing of composite materials. Lancaster, PA: DEStech Publications, Inc, 2009.

8. Thomason JL. The influence of fibre length, diameter and concentration on the strength and strain to failure of glass-fibre reinforced Polyamide 6,6. Compos A Appl Sci Manuf 2008; 39: 1618-1624.

9. Vincent M, Giroud T, Clarke A, et al. Description and modeling of fiber orientation in injection molding of fiber reinforced thermoplastics. Polymer 2005; 46: 6719-6725.

10. Kardos JL. Critical issues in achieving desirable mechanical properties for short fiber composites. Pure Appl Chem 1985; 57: 1651-1657.

11. Kanouté P, Boso DP, Chaboche JL, et al. Multiscale methods for composites: a review. Arch Comput Meth Eng 2009; 16: 31-75.

12. Tucker CL III and Liang E. Stiffness predictions for unidirectional short-fiber composites: review and evaluation. Compos Sci Tech 1999; 59: 655-671.

13. Cox HL. The elasticity and strength of paper and other fibrous materials. $\mathrm{Br} J$ Appl Phys 1952; 3: 72.

14. Rosen BW. Tensile failure of fibrous composites. AIAA J 1964; 2: 1985-1991.

15. Voigt W. Lehrbuch Der Kristallphysik. Stuttgart: B.G. Teubner, 1910.

16. Reuss A. Berechnung der Fließgrenze von Mischkristallen auf Grund der Plastizitätsbedingung für
Einkristalle. ZAMM J Appl Math Mech (Zeitschrift für angewandte Mathematik und Mechanik) 1929; 9: 49-58.

17. Reuss A. Berücksichtigung der elastischen Formänderung in der Plastizitätstheorie. ZAMM J Appl Math Mech (Zeitschrift für angewandte Mathematik und Mechanik) 1930; 10: 266-274.

18. Hashin $\mathrm{Z}$ and Shtrikman S. A variational approach to the theory of the elastic behaviour of multiphase materials. J Mech Phys Solid 1963; 11: 127-140.

19. Lielens G, Pirotte P, Couniot A, et al. Prediction of thermo-mechanical properties for compression moulded composites. Compos A Appl Sci Manuf 1998; 29: 63-70.

20. Hill R. A self-consistent mechanics of composite materials. J Mech Phys Solid 1965; 13: 213-222.

21. Benveniste Y. A new approach to the application of Mori-Tanaka's theory in composite materials. Mech Mater 1987; 6: 147-157.

22. Tandon GP and Weng GJ. The effect of aspect ratio of inclusions in the elastic properties of unidirectionally aligned composites. Polymer Compos 1984; 5: 327-333.

23. Thomasson JL and Vlug MA. Influence of fibre length and concentration on the properties of glass fibre-reinforced polypropylene: 1 . Tensile and flexural modulus. Compos A Appl Sci Manuf 1996; 27: 477-484.

24. Fu SY and Lauke B. Effects of fiber length and fiber orientation distributions on the tensile strength of short-fiber-reinforced polymers. Compos Sci Tech 1996; 56: $1179-1190$.

25. Kim JW and Lee DG. Fiber orientation state depending on the injection mold gate variations during FRP injection molding. Key Eng Mater 2006; 321-323: 938-941.

26. Chou TW and Nomura S. Fibre orientation effects on the thermoelastic properties of short-fibre composites. Fibre Sci Tech 1980; 14: 279-291.

27. Talbott MF, Springer GS and Berglund LA. The effects of crystallinity on the mechanical properties of PEEK polymer and graphite fiber reinforced PEEK. J Compos Mater 1987; 21: 1056-1081.

28. Thomasson JL. The influence of fibre length and concentration on the properties of glass fibre reinforced polypropylene: 5. Injection moulded long and short fibre PP. Compos A Appl Sci Manuf 2002; 33: 1641-1652.

29. Boey FYC. Reducing the void content and its variability in polymeric fibre reinforced composite test specimens using a vacuum injection moulding process. Polymer Test 1990; 9: 363-377.

30. El Kadi $\mathrm{H}$ and Denault J. Effects of processing conditions on the mechanical behavior of carbon-fiberreinforced PEEK. J Thermoplast Compos Mater 2001; 14: 34-52.

31. Park K and Kim YS. Effects of mold temperature on mechanical properties of an injection-molded part with microfeatures. J Polymer Eng 2009; 29: 135-153.

32. Pechulis $M$ and Vautour D. The effect of thickness on the tensile and impact properties of reinforced thermoplastics. J Reinforc Plast Compos 1998; 17: $1580-1586$.

33. Sarasua JR, Remiro PM and Pouyet J. Effects of thermal history on mechanical behavior of PEEK and its shortfiber composites. Polymer 1996; 17: 468-477. 
34. Chen $\mathrm{CH}$ and Cheng $\mathrm{CH}$. Effective elastic moduli of misoriented short-fiber composites. Int J Solid Struct 1996; 33: 2519-2539.

35. Termonia Y. Structure-property relationships in shortfiber-reinforced composites. J Polymer Sci B Polymer Phys 1994; 32: 969-979.

36. Christensen RM, Schantz $\mathrm{H}$ and Shapiro J. On the range of validity of the Mori-Tanaka method. J Mech Phys Solid 1992; 40: 69-73.

37. Pierard O, Friebel C and Doghri I. Mean-field homogenization multi-phase thermo-elastic composites: a general framework and its validation. Compos Sci Tech 2004; 64: 1587-1603.

38. Vu-Khanh $\mathrm{T}$ and Denault J. Effect of molding parameters on the interfacial strength in PEEK/carbon composites. J Reinforc Plast Compos 1993; 12: 916-931.

39. Hour KY and Sehitoglu H. Damage development in a short fiber reinforced composite. J Compos Mater 2003; 27: 782-805.

40. Fitoussi J, Gao G and Baptiste D. Determination of a tridimensional failure criterion at the fibre/matrix interface of an organic-matrix/discontinuous-reinforcement composite. Compos Sci Tech 1996; 56: 755-760.

41. ASTM D3641-10a. Standard practice for injection molding test specimens of thermoplastic molding and extrusion materials. West Conshohocken, PA: ASTM International, 2010.

42. Sabre T. Plans d'expériences - Méthode de Taguchi. Techniques de l'Ingénieur, F1006 2007.

43. Wesselman MH. Impact of the moulding conditions on the properties of short fibre reinforced high performance thermoplastic parts. Thesis, Université de Toulouse, Toulouse, 2003.

44. Saint-Martin G, Schmidt F, Devos P, et al. Voids in short fibre-reinforced injection-moulded parts: density control vs. mass control. Polymer Test 2003; 22: 947-953.

45. Saint-Martin G. Étude typologique des défauts structuraux générés au cours de la mise en forme par injection de composites à matrice polymère thermostable renforcés par fibres de verre courtes. $\mathrm{PhD}$ Thesis, Université de Toulouse, Toulouse, 2003.

46. Haramburu E. Approche intégrée du dimensionnement mécanique de structures en composite injecté avec fibres courtes: une interface entre injection et calcul de structure. $\mathrm{PhD}$ Thesis, Université de Toulouse, Toulouse, 2003.

47. Bessard E, De Almeida O and Bernhart G. Melt state behaviour of PEEK and processing window interpretation for fast compression moulding process. In: Proceedings of international conference on advances in materials and processing technologies, Paris, France, 24-27 October 2010.

48. NF ISO 527-2. Détermination des propriétés en tractionPartie 2: Conditions d'essai des plastiques pour moulage et extrusion. 2012. Afnor, 11 Rue Francis De Pressensé 93571 La Plaine Saint Denis Cedex France.

49. Mori $\mathrm{T}$ and Tanaka $\mathrm{K}$. Average stress in matrix and average elastic energy of materials with misfitting inclusions. Acta Metallurgica 1973; 21: 571-574.

50. Eshelby JD. The determination of the elastic field of an ellipsoidal inclusion and related problems. Proc Roy Soc Lond Math Phys Sci 1957; 241: 376-396.

51. Meraghni F, Desrumaux $F$ and Benzeggagh ML. Implementation of a constitutive micromechanical model for damage analysis in glass mat reinforced composite structures. Compos Sci Tech 2002; 62: 2087-2097.

52. Lachaud F. Délaminage de matériaux composites à fibres de carbone et à matrices organiques: Étude numérique et expérimentale, suivi par émission acoustique. French $\mathrm{PhD}$ Thesis, Toulouse University, Toulouse, 1997.

53. Friedrich K, Walter R, Voss H, et al. Effect of short fibre reinforcement on the fatigue crack propagation and fracture of PEEK-matrix composites. Composites 1986; 17: 205-216.

54. Kim JK and Gao SL. Interface adhesion and interlaminar fracture resistance of carbon/PEEK composites influenced by cooling rate. Key Eng Mater 2000; 183-187: 1063-1068. 